\title{
Ophthalmic regional blocks: management, challenges, and solutions
}

\author{
This article was published in the following Dove Press journal: \\ Local and Regional Anesthesia \\ 20 August 2015 \\ Number of times this article has been viewed
}

\author{
Howard D Palte \\ Department of Anesthesiology, \\ Perioperative Medicine and Pain \\ Management, Miller School of \\ Medicine, University of Miami, Miami, \\ FL, USA
}

\begin{abstract}
In the past decade ophthalmic anesthesia has witnessed a major transformation. The sun has set on the landscape of ophthalmic procedures performed under general anesthesia at inhospital settings. In its place a new dawn has ushered in the panorama of eye surgeries conducted under regional and topical anesthesia at specialty eye care centers. The impact of the burgeoning geriatric population is that an increasing number of elderly patients will present for eye surgery. In order to accommodate increased patient volumes and simultaneously satisfy administrative initiatives directed at economic frugality, administrators will seek assistance from anesthesia providers in adopting measures that enhance operating room efficiency. The performance of eye blocks in a holding suite meets many of these objectives. Unfortunately, most practicing anesthesiologists resist performing ophthalmic regional blocks because they lack formal training. In future, anesthesiologists will need to block eyes and manage common medical conditions because economic pressures will eliminate routine preoperative testing. This review addresses a variety of topical issues in ophthalmic anesthesia with special emphasis on cannula and needlebased blocks and the new-generation antithrombotic agents. In a constantly evolving arena, the sub-Tenon's block has gained popularity while the deep angulated intraconal (retrobulbar) block has been largely superseded by the shallower extraconal (peribulbar) approach. Improvements in surgical technique have also impacted anesthetic practice. For example, phacoemulsification techniques facilitate the conduct of cataract surgery under topical anesthesia, and suture-free vitrectomy ports may cause venous air embolism during air/fluid exchange. Hyaluronidase is a useful adjuvant because it promotes local anesthetic diffusion and hastens block onset time but it is allergenic. Ultrasound-guided eye blocks afford real-time visualization of needle position and local anesthetic spread. An advantage of sonic guidance is that it may eliminate the hazard of globe perforation by identifying abnormal anatomy, such as staphyloma.
\end{abstract}

Keywords: ophthalmic anesthesia, venous air embolism, anticoagulation, hyaluronidase, ultrasound, ocular trauma

\section{Introduction}

In the last 25 years, the focus of global health care efforts has been directed at primary and preventative medicine with great emphasis placed on stricter control of metabolic disorders. The outcomes of these endeavors are evidenced by measurable metrics, such as reductions in infant mortality and extended life expectancy. This means that in future, anesthesiologists will care for a greater number of geriatric patients, and many of these elderly folk will present for eye surgery with significant preexisting comorbidities that favor the use of regional techniques. Furthermore, economic pressures such as cost-containment, operating room (OR) efficiency, and a greater focus
Correspondence: Howard D Palte Bascom Palmer Eye Institute, 900 NW 17th Street, 6th Floor, Miami, FL 33I36, USA

Email hpalte@med.miami.edu 
on patient outcomes will mandate that anesthesiologists become team leaders and assume responsibility for both perioperative management and the performance of eye blocks. This review addresses a selection of regional ophthalmic anesthesia-related topics ranging from common issues such as the management of patients on oral anticoagulants (Acs), occasional hyaluronidase (HA) allergy, and considerations favoring the use of ultrasound guidance to enhance the quality and safety of eye blocks. The newer antithrombotic agents are covered in some detail because they are widely used, and unlike the older antithrombotics, require no monitoring of bleeding indices.

\section{Training}

Ophthalmic surgical procedures account for a sizeable proportion of all surgeries performed worldwide. In the USA, more than three million cataract lenses are extracted on an annual basis. ${ }^{1}$ The ever burgeoning geriatric population will impact future anesthesia practice profiles because providers will need to care for a greater number of elderly patients presenting for eye surgery. Currently, it is common practice that the anesthesiologist provides monitored anesthesia care with performance of the eye block defaulting to the ophthalmologist. This state of affairs exists because many anesthesiologists consider themselves inadequately trained in eye block techniques. Unfortunately, fewer than $25 \%$ of anesthesiology residency programs provide hands-on clinical instruction in ophthalmic regional anesthesia. ${ }^{2}$ Anesthesiologists avoid performing eye blocks because of the perceived risk of globe perforation, muscle damage, and optic nerve injury. This misperception has been propagated by two 1990s publications that documented multiple cases of globe penetration following blocks performed by anesthesiologists. ${ }^{3,4}$ In these cases, the doctors received little or no formal training in eye block techniques, and patients suffered permanent visual loss. In view of ongoing training deficiencies, it is not surprising that eye block complications continue to constitute a measurable proportion of closed claim monitored anesthesia care cases. ${ }^{5,6}$ Furthermore, anesthesiologists lack motivation to enroll in instructional courses because there is no additional remuneration for performing eye blocks. Despite this, anesthesiologists remain the most knowledgeable and skilled physicians in most areas of regional anesthesia.

It is encouraging to note that trends are changing and that increasing number of anesthesiologists are now performing eye blocks. Many years ago, ophthalmologists began to relocate their surgical cases from an in-hospital setting to ambulatory centers, and more recently, to specialty eye care surgery centers. It is accepted that early intervention (block) in the preoperative holding suite improves OR efficiency. Moreover, anesthesiologists are shifting away from retrobulbar (intraconal) to peribulbar (extraconal) procedures because needles are kept at a greater distance from the globe and vital adnexa. Since peribulbar anesthesia has a prolonged latency, it is advantageous to perform the block at least 10 minutes prior to the commencement of surgery. In fact, many ophthalmologists and ambulatory center administrators favor performance of blocks in the holding room as a means of improving OR turnover times, assuring excellent intraoperative ocular akinesia, increasing surgical volumes, and enhancing OR efficiency.

Regrettably, anesthesia trainees are afforded limited opportunity to acquire skills in ophthalmic regional anesthesia because of dwindling volumes of eye surgeries at in-hospital settings. Furthermore, the advent of minimally invasive phacoemulsification techniques has resulted in topical anesthesia as a viable alternative for most cataract surgeries. Additionally, ophthalmology residents gain minimal regional block experience because anesthesiologists perform these blocks at the academic eye centers. The paucity of formal regional ophthalmic anesthesia training is of concern because eye surgery is so common. In meeting future needs, the challenge facing our specialty will be to redouble educational efforts by increasing the number of didactic lectures and hands-on instructional courses. The ability to perform safe, effective regional ophthalmic anesthesia will be an obligatory component of future anesthesia training. Economic pressures will result in the greater use of eye blocks with general anesthesia (GA) being reserved for pediatric and deserving adult cases.

\section{Ocular trauma General considerations}

Ocular trauma is a universal problem and affects all ages. In the USA, there are more than one million emergency department eye injury admissions annually, the most frequent being superficial insults with open wounds accounting for only $10 \%$ of cases. ${ }^{7}$ An understanding of ocular anatomy and physiology, especially regulation of intraocular pressure (IOP), is a key to anesthesia planning because several agents exert deleterious IOP effects that may impair visual outcome. The primary anesthesia goals in trauma victims include airway security and prevention of gastric aspiration. However, in ocular trauma it is vital to avoid rapid increases in IOP that result in extrusion of ocular contents. These considerations obligate the anesthesiologist to institute measures 
that prevent patients from coughing, straining, retching, or squeezing their eyelids.

\section{Succinylcholine and the open globe}

Formerly, it was postulated that the administration of succinylcholine resulted in acute and significant rises in IOP, presumably through forces generated by extraocular muscle fasciculation. This doctrine emanated from three anecdotal 1950s case reports that erroneously linked perioperative extrusion of ocular contents to the administration of succinylcholine. ${ }^{89}$ In 1982, investigators at Wills Eye Hospital performed a retrospective review of 100 trauma cases. Sixty three of these patients received succinylcholine as a component of their anesthesia, and based on descriptions in the operative report none suffered global extrusion. ${ }^{10}$ In a further study, Libonati et al found that the administration of succinylcholine caused IOP to increase by approximately $9 \mathrm{mmHg}$, and that increases start within 1 minute and peak at 6 minutes. ${ }^{11}$ It is postulated that IOP changes are induced either by vascular dilation of the choroidal vasculature or impedance of venous drainage, resulting in raised central venous pressure. Importantly, increases in IOP associated with the administration of succinylcholine are significantly less than those associated with forceful blinking, crying, retching, coughing, and bucking, all actions that may occur with suboptimal intubation conditions. This effectively means that changes in IOP occurring secondary to the administration of succinylcholine are of minimal clinical importance.

Traditionally, GA has been the preferred technique for open globe injuries with intravenous sedation and regional anesthesia reserved for patients considered at risk under GA. Proponents for the mandatory use of GA in open globe injuries base their argument on the importance of avoiding patient movement, coughing, or bucking because acute increases in IOP may be associated with extrusion of ocular contents and poor visual outcome. This argument is countered by assertions that acute elevations in IOP may also result from hemodynamic changes induced by laryngoscopy and tracheal intubation.

In 1997, Pieramici et al proposed a classification of mechanical eye injuries according to type (mechanism), grade (visual acuity), zone, and pupillary defect. ${ }^{12}$ This classification was validated by a subsequent study that demonstrated a prognostic correlation between the initial evaluation and final visual acuity. Adopting this classification, physicians at Bascom Palmer Eye Institute implemented locoregional anesthesia for select (anterior) open eye injuries. Scott et al conducted a retrospective analysis of visual outcomes in traumatic open eye injuries treated between 1995 and 1999. ${ }^{13}$ Of the 218 cases reviewed, almost two-thirds (64\%) were managed with intravenous sedation and local anesthesia. In these cases, small volumes of local anesthesia $(<5 \mathrm{~mL})$ were injected slowly under direct visualization of the globe in order to monitor wound stability. In the OR, a conjunctival cut down was performed and the block was supplemented with cannula irrigation of small volumes $(1-2 \mathrm{~mL})$ of local anesthetic (LA). This study found that the patients in the LA/ sedation group were more likely to have an intraocular foreign body (IOFB), better initial visual acuity, and more anterior wound locations, whereas the GA group had more extensive ocular trauma. The amassed data indicated that the local anesthesia/sedation group had significantly shorter operating times $(P<0.001)$ and shorter postoperative follow-up periods $(P=0.002)$ and failed to demonstrate differences in long-term visual outcome $(P=0.16)$.

Subsequently, Scott et al performed a retrospective study of 238 open globe injuries treated between 2000 and 2003 and found that patients managed with sedation and locoregional anesthesia were more likely to have anterior wounds $(P<0.001)$ and less likely to have an afferent pupillary defect $(12 \%$ vs $43 \%) .{ }^{14}$ In this study, the use of local anesthesia was not associated with the increased risk of extrusion of globe contents and did not result in impairment in long-term visual outcome. Many centers continue to manage ocular trauma under GA because providers are uncomfortable administering blocks to the traumatized eye. However, these studies and the ongoing clinical experience indicate that regional anesthesia is a viable option for the repair of select (anterior) open eye injuries, especially in cases where GA carries risk.

\section{Venous air embolism}

In 1912, Brandes accidentally demonstrated the mechanism of venous air embolism (VAE), when he injected bismuth paste into the thoracic sinus while attempting to demonstrate the extent of an empyema. Since then VAE has been reported in a host of different surgeries. VAE occurs secondary to the entrainment of air (or exogenous gas) from the operative field into the venous or arterial circulation, and is associated with any surgery where the wound is at a level above the heart, such as seated craniotomy. The clinical presentation depends on the amount of air entrained and the rate at which it enters the circulation, larger volumes of gas $(>200 \mathrm{~mL})$ being potentially lethal. ${ }^{15}$ Fortunately, volumes entrained are often small and entrainment passes undetected. However, VAE can occur during procedures in which the patient's position produces a similar gravitational danger (Trendelenburg or lateral decubitus), 
and in surgeries involving highly vascularized areas (tumors, malformations), or vascular compromise (trauma).

\section{VAE and eye surgery}

In 2005, the first report of eye surgery-related VAE appeared in the literature. ${ }^{16}$ In his report, Ledowski et al documented a case in which there was a sudden and profound circulatory collapse during the air/fluid exchange (OAFE) phase of retinal detachment surgery. The clinical diagnosis was made on the presenting symptoms, and the presence of a "millwheel" murmur on precordial auscultation. Ledowski et al postulated that the air passaged from the infusion cannula into an open choroidal vein and then onward to the central circulation. In 2007, another case report appeared in which VAE occurred in a 17-month-old boy during repair of an open traumatic eye injury. ${ }^{17}$ In this case, an IOFB impaled the optic nerve, and in an attempt to avert hemorrhage from the central retinal vessels, the infusion pressure was increased to almost $90 \mathrm{~mm} \mathrm{Hg}$. It was postulated that air was entrained into the central circulation via the central retinal vein. In 2008, another report documented VAE in a 51-year-old man undergoing surgical removal of an IOFB. ${ }^{18}$ It is interesting that in this case the circulatory collapse also occurred during OAFE. Importantly, VAE is not necessarily an anterograde phenomenon but can "follow retrograde venous and arterial routes, even epidural routes." In reviewing these cases, Lim et al commented that many ophthalmologists are unaware of this rare complication and its relation to the OAFE phase. ${ }^{19}$ They opined that the anesthesiologist is obliged to alert the ophthalmologist of this rare complication, and inform him that immediate termination of the air infusion and refilling of the eye with fluid can abort a full-blown syndrome and limit systemic morbidity.

In 2014, Morris et al conducted an in vitro experiment to determine whether accidental infusion of air into the suprachoroidal space could produce gaseous egression from the vortex veins. ${ }^{20}$ Using a total of four banked enucleated eyes; he performed sequential vitrectomies using a standard technique. During the procedure, he purposefully withdrew the infusion cannula to stimulate the clinical scenario where the unsecured cannula accidentally slips outward (Figure 1). In the first three eyes, he started the OAFE at air pressures between $30 \mathrm{mmHg}$ and $60 \mathrm{mmHg}$. The air entered the vitreous cavity and produced detachment of the choroid. Following this, he transported the eyes to an adjacent water bath and immersed them up to their equators such that the vortex vein stumps were submerged, but the surgical incisions were "high and dry". In the first three eyes, air bubbled upward from the submerged sclera at a rate proportional to the applied pressure.

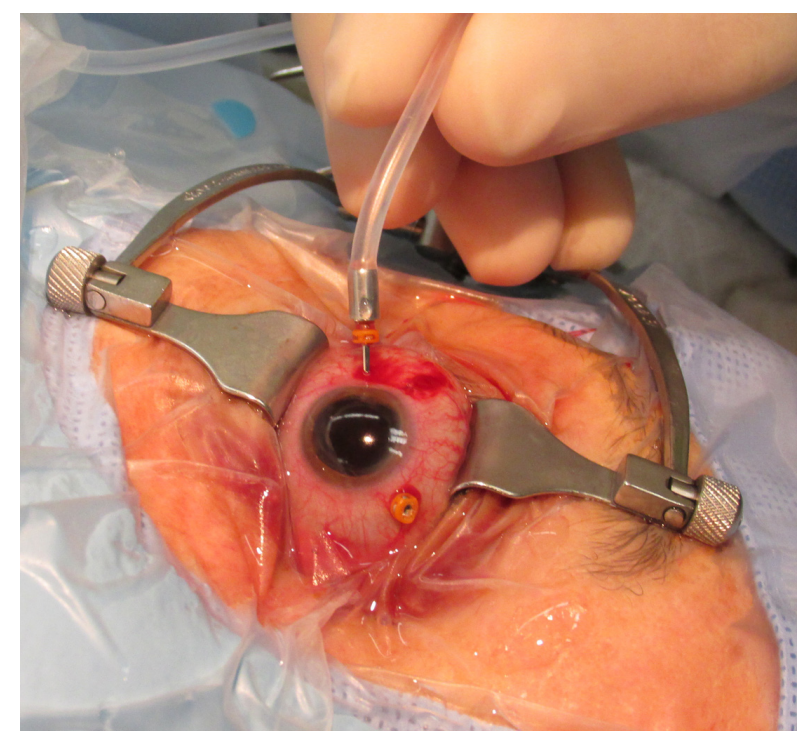

Figure I Intraoperative image of an unsutured infusion cannula slipping outward during vitrectomy.

In the fourth eye, he applied clamps to the four vortex veins before proceeding with surgery. When this eye was submerged no air bubbled through. However, on release of the vortex clamps, air bubbles reappeared. Morris et al hypothesized that OAFE produces fatal VAE from tearing of the vortex veins during misguided infusions of air. Currently, there is no in vivo investigation to corroborate this hypothesis.

\section{Oral Acs}

A major challenge for the ophthalmic anesthesiologist is the perioperative management of eye surgery patients on Ac and antiplatelet (Ap) therapies. Today, more than 40 million Americans take aspirin and approximately 5 million are on long-term Ac therapy. ${ }^{21}$ These medications are administered for stroke prevention, atrial fibrillation, and venous thromboembolism (VTE). Furthermore, Ac therapies are prophylactically administered to prevent clotting of mechanical heart valves and mitigate secondary effects of cardiovascular disease. Since their administration increases the risk of bleeding, a determination must be made whether to continue therapy in the perioperative period considering the inherent sightthreatening risks of intraorbital hemorrhage. Furthermore, in selecting regional anesthesia, the anesthesiologist must determine whether to perform a needle-based block or select alternate regional techniques, such as the cannula-based subTenon's block (STB) or default to GA.

\section{Ap drugs}

\section{Aspirin and thienopyridines}

Since the 1980s, aspirin has been the mainstay in management of stable coronary disease and acute coronary syndrome (ACS). 
Aspirin inactivates platelet cyclooxygenase (COX)-1 and inhibits production of thromboxane. In 2005, almost one-fifth of US adults, mainly over 65 years, reported using aspirin on a daily basis. Aspirin is frequently given in combination with either clopidogrel (Plavix ${ }^{\circledR}$ ) or ticlopidine $\left(\right.$ Ticlid $^{\circledR}$ ). These thienopyridine derivatives act as irreversible inhibitors of the platelet $\mathrm{P} 2 \mathrm{Y} 12$ receptor. The aspirin/thienopyridine combination is used for the prevention of athero-thrombotic events in patients with coronary artery stents. Both clopidogrel and ticlopidine have no effect on COX-1 activity and act independently of aspirin, and their inhibition of platelet-fibrinogen binding and platelet-platelet interaction is irreversible for the life of the platelet. The clinical importance is that platelet dysfunction persists for 5-7 days following discontinuation of clopidogrel, and 10-14 days after ticlopidine. A new thienopyridine, prasugel $\left(\right.$ Effient $^{\mathbb{B}}$ ) is a prodrug that on activation acts as an ADP receptor antagonist. Prasugel binds irreversibly to the P2Y12 receptor and offers the advantage of increased potency, rapid onset, and more predictable effect. Ticagrelor $\left(\right.$ Brilinta $^{\circledR}$ ) is an oral P2Y12 antagonist that is rapidly absorbed and reaches peak plasma levels within 1.5 hours.

\section{Glycoprotein Ilb/IIla receptor antagonists}

The platelet glycoprotein IIB/IIIa receptor antagonists inhibit platelet aggregation by interfering with platelet-fibrinogen binding and platelet-platelet interaction. Agents in this group include eptifibatide (Integrilin ${ }^{\circledR}$ ), abciximab (Reopro ${ }^{\circledR}$ ), and tirofiban (Aggrastat ${ }^{\mathbb{R}}$ ). The clinical significance of these agents is that the platelet function remains impaired for 8-48 hours following discontinuation.

\section{Ac drugs \\ Older agents}

Warfarin (coumadin)

Warfarin inhibits the production of vitamin K-dependent clotting factors (II, VII, IX, and X) and the Ac proteins C and S. It is used in the treatment of VTE and prophylaxis against embolism in patients with prosthetic heart valves, valvular rheumatic heart disease, atrial fibrillation, and cerebral transient ischemic attacks.

\section{Heparin}

Heparin has been successfully used in the prevention and treatment of VTE, unstable angina, myocardial infarction and postinfarction mural thrombus.

Both unfractionated and fractionated low molecular weight heparin bind the enzyme inhibitor antithrombin III (AT). This results in the activation of AT and subsequent inhibition of thrombin and other proteases. Fondaparinux (Arixtra $\left.{ }^{\circledR}\right)$ is a LMWH that produces its antithrombotic effect through factor Xa inhibition. Its plasma half-life of 21 hours facilitates single daily dosing.

\section{Nonsteroidal anti-inflammatory drugs}

Nonsteroidal anti-inflammatory drugs inhibit the activity of both the COX-1 and COX-2 enzyme, resulting in impaired synthesis of prostaglandins and thromboxanes. At lower doses they have analgesic and antipyretic effects, while at higher doses they act as anti-inflammatory agents. Patients taking NSAIDs are not at significant risk of postblock orbital hemorrhage.

\section{Newer agents}

The newer Ac agents are widely prescribed because of superior efficacy in the treatment of atrial fibrillation, and because they require no serial monitoring of coagulation parameters. In the USA, the FDA has approved new-generation Acs in the management of VTE, atrial fibrillation, after joint replacement surgery, and in the active treatment of VTE. Warfarin has been the traditional therapy for these conditions, but its use imposes the additional burden of periodic International Normalized Ratio (INR) monitoring. Additionally, it has the limitation that INR is only maintained within the recommended therapeutic range $(2.0-3.0)$ in $60 \%$ of patients.

\section{Dabigatran (Pradaxa ${ }^{\circledR}$ )}

Dabigatran is a prodrug and direct thrombin inhibitor that is activated by stomach esterases. It blocks the interaction of thrombin with various substrates and prevents the conversion of fibrinogen to fibrin. In patients with atrial fibrillation, dabigatran was found to diminish the rate of stroke and systemic embolism to the same degree as warfarin but with a lower frequency of intracranial hemorrhage. ${ }^{22}$ However, when added to dual platelet therapy in patients with coronary artery disease, dabigatran increased the rate of bleeding events without reducing the rate of cardiovascular ischemia. ${ }^{23}$ Its half-life is 8 hours after a single dose but may be as long as 17 hours after multiple doses. Dabigatran prolongs the activated partial thromboplastin time and reversal is possible with recombinant factor VIIa.

\section{Rivaroxaban (Xarelto ${ }^{\circledR}$ )}

This is a direct inhibitor of factor Xa with a rapid onset of action and peak plasma levels are reached in 3-4 hours. Concomitant use of rivaroboxan with aspirin or naproxen has no additive effect on platelet aggregation. ${ }^{24}$ In the treatment of VTE, its efficacy is claimed to match enoxaparin. ${ }^{25}$ 
In patients with recent $\mathrm{ACS}$, the addition of rivarobaxan to standard Ap therapy reduced deaths from stroke and infarction. ${ }^{26}$

\section{Apixaban (Eliquis ${ }^{\circledR}$ )}

Apixaban is a selective inhibitor of factor Xa that is rapidly absorbed, reaching peak plasma levels within 2 hours. In patients with atrial fibrillation who are not candidates for vitamin $\mathrm{K}$ antagonists, apixaban was superior to aspirin in reducing stroke rate. ${ }^{27}$ It is also superior to warfarin in preventing stroke or systemic embolism. ${ }^{28}$

Ophthalmic surgeons are often confronted with the dilemma of continuing or suspending antithrombotic agents before surgery. Similarly, anesthesiologists must assess whether the benefits of regional anesthesia outweigh the risks of orbital hemorrhage. In a prospective study, Calenda et al assessed the safety of continuing oral anticoagulation in patients receiving peribulbar blocks. ${ }^{29}$ Hemorrhages were classified according to four groups depending on their site, severity, and risk of compromise of vision. He concluded that the continuation of preoperative oral Acs was an acceptable risk because the overall incidence in the anticoagulation group was $2 \%$ compared to $1.7 \%$ in the control group. Furthermore, he noted that no serious (Grade 3 or 4) hemorrhages were encountered in either population. Brown and Mahmoud performed a retrospective analysis of posterior segment surgeries performed by a single surgeon over a 30 -month period. ${ }^{30}$ Of the cases reviewed, 27 remained on anticoagulation therapy, and none experienced hemorrhagic complications. Similarly, Mason et al reported no complications in a retrospective series of 64 peribulbar blocks performed in patients taking warfarin. ${ }^{31}$ In a group of 76 patients, Kallio et al found a 3.9\% incidence of hemorrhage after peribulbar block and concluded that the continuation of warfarin does not predispose to bleeding complications. ${ }^{32}$ In an audit of the United Kingdom Cataract National dataset, Benzimra identified almost 2,500 patients treated with warfarin and found that although the there was an increased incidence of subconjunctival hemorrhage (3.7\%), there were no instances of retrobulbar hemorrhage. ${ }^{33}$

Although preoperative discontinuation of oral Acs diminishes the risk of ocular hemorrhage, it may increase the risk of cardiovascular complications such as stroke or infarction. Therefore, it is beneficial to assign risk in line with individual patient and procedure factors. Patient risk factors should be guided by consideration of the underlying reasons for anticoagulation therapy and recommendations from an internist. For example, patients taking Acs for a history of coronary artery disease may be candidates for interval therapy suspension while patients treated for recent placement of a drug-eluting stent may pose too great a risk to warrant cessation of therapy. In vitreoretinal surgery, the risk of hemorrhage varies according to the underlying pathology. This means that a vascular disorder, such as diabetic retinopathy, poses a greater bleeding threat than retinal detachment surgery. Importantly, bleeding secondary to Ap therapy is inconsequential because all reported hemorrhages show spontaneous resolution with no long-term visual sequelae.

Currently, practice guidelines favor the continuation of Acs in the perioperative period because discontinuation can be life threatening. Cataract and anterior chamber surgeries are considered "low risk" because they involve avascular structures. However, vitreoretinal surgery often involves manipulation of vessel-rich tissue with the possibility of hemorrhage. In a retrospective study, Oh et al evaluated the prevalence of Ap and anticoagulation therapy in patients having retinal surgery and the relationship between their administration and postoperative bleeding. ${ }^{34}$ In reviewing the records of 822 patients between 2004 and 2008, he found a trend toward the increased use of Ap medications but found no change in trends for warfarin. Interestingly, the study failed to demonstrate that continuing Ap therapy increased the risk of postoperative hemorrhage. However, decisions regarding warfarin are more difficult because these patients are at higher risk of catastrophic thromboembolic events. Finally, Oh et al documented no cases where either surgical failure or significant morbidity was directly attributable to perioperative bleeding.

In a recent review, Gerstein et al advocated the continued administration of aspirin in the perioperative period but excluded cases where excessive blood loss could "lead to worse outcomes related to morbidity and mortality." 35 In this category, he lumped posterior segment eye surgery with spinal and intracranial procedures. Similarly, Baron et al opined that vitreoretinal surgery should be categorized as "high risk" of bleeding complications. ${ }^{36}$ Hemorrhagic complications associated with needle-based eye blocks, ranging from ecchymoses to vision-threatening retrobulbar hemorrhage, are rare and seldom of long-term consequence. For this reason, the opinions expressed by Gerstein and Baron do not garner the support of many vitreoretinal surgeons who contend that benefits of continuing Acs outweigh risks associated with their discontinuation. Furthermore, they favor the continuation of antithrombotics throughout the perioperative period because hemorrhagic complications have minimal impact on visual outcome. ${ }^{37}$ However, in urgent or complex 
surgery it is prudent to discuss the benefit to risk ratio with an internist or cardiologist. ${ }^{38}$

\section{Ultrasound-guided eye blocks}

Ophthalmic regional anesthesia is not without risk. Longterm visual compromise secondary to needle misadventure, resulting in penetration or perforation of the globe, is the most feared complication in ophthalmic anesthesia. Needle blocks, by definition, are unsighted and rely on operator knowledge of surface anatomical landmarks in order to correctly position the needle. Ultrasound technology is an integral component of the ophthalmologist's evaluation of the eye, but its application to ophthalmic regional anesthesia remains limited. The potential benefits of ultrasound guidance include real-time visualization of needle trajectory and spread of injected local anesthetic, resulting in blocks of improved quality and safety.

The orbit is well suited to ultrasound investigation. The bony lateral walls form an eccentric quadrangular pyramid with its apex posteromedially. Using B-mode ultrasound, the axial length is easily measured from the anterior surface of the cornea to the macula. The eye appears as a round hypoechoic structure (globe and vitreous) with the sclera forming a hyperechogenic perimeter.

Unsighted needle-based blocks are guided by operator experience and estimates of globe size. Birch et al investigated the accuracy of needle placement during the performance of routine eye blocks and used ultrasound imagery to demonstrate the true needle position. ${ }^{39} \mathrm{He}$ recruited ophthalmologists, experienced in the performance of retrobulbar blockade, and asked them to place the needle $5 \mathrm{~mm}$ posterior to the globe. He then obtained sonic confirmation of needle position and demonstrated that the needle was uniformly closer to the globe than estimated. The true needle tip to sclera distances ranged from $0.2 \mathrm{~mm}$ to $3.3 \mathrm{~mm}$. Although no globe perforations were encountered, the needle shaft was seen to indent the globe in more than half of the cases.

A preblock scan of the globe and adnexa may be fruitful, particularly in myopic patients. The risk of globe perforation is up to 30 times greater in severe myopia because of lengthening of the globe. Additionally, the risk of perforation is increased by staphyloma, an out-pouching of the globe secondary to severe thinning of the sclera, choroid, and retina. Vohra and Good used B-mode ultrasound to study the incidence and the position of staphylomas in 100 myopic patients. ${ }^{40}$ They found a staphyloma incidence of $0 \%$ when the axial length was less than $27 \mathrm{~mm}, 37 \%$ when axial length was between $27 \mathrm{~mm}$ and $31 \mathrm{~mm}$, and 60\% when the axial length exceeded $31 \mathrm{~mm}$. Contrary to popular belief, Vohra and Good found that staphylomas are not necessarily posterior to the globe; in her series, $82 \%$ were located in the infero-temporal region. Interestingly, most staphylomas were not detected at routine sonic evaluation. Finally, real-time visualization of the block can provide new information about LA spread and mechanisms of anesthesia. A recent report demonstrated that LA injected within the muscle cone and behind the eye is able to enter the posterior component of Tenon's space and track in an anterograde direction producing chemosis of the subconjunctival space. ${ }^{41}$

Winder et al used ultrasonography to study LA spread during retrobulbar (intraconal), peribulbar (extraconal) blocks, and STBs. ${ }^{42} \mathrm{He}$ performed sonic evaluations prior to, during, and 10 minutes after injection of LA. As expected, anechoic LA was visualized within the muscle cone during retrobulbar block and outside of the cone for peribulbar blocks. However, at 10 minutes, he demonstrated that extraconal LA traversed the muscle cone and entered the intraconal space. Furthermore, he demonstrated that the echo-void LA formed a " $T$ " sign outlining the optic nerve. This study provided visual confirmation that peribulbar block produces anesthesia in a similar manner to retrobulbar block, albeit with a greater latency of onset. Luyet et al performed an elegant series of 20 ultrasound-guided needle-based blocks on ten cadaveric specimens. ${ }^{43}$ Using a long-axis approach and curved array transducer, he introduced a $22 \mathrm{G}$ short bevel needle until the needle tip was $2 \mathrm{~mm}$ from the optic nerve. At this point, $2 \mathrm{~mL}$ contrast dye was injected and its spread was documented through a series of computed tomography scans. This investigation confirmed the benefit of ultrasound-guided eye blocks because key structures, such as globe, optic nerve, needle, and spread of local anesthetic, were easily visualized.

The application of sonic energy to the eye is not without risk. The eye is a vulnerable organ, especially to thermal and mechanical damage from excessive sound energy. Therefore, consideration must be given to the ocular bioeffects of ultrasound before endorsing its application for eye blocks in daily practice. Multiple international regulatory authorities, including the US Food and Drug Administration, Health Canada, and the British Medical Ultrasound Society, have imposed stricter physical parameters for the use of ophthalmic ultrasound. Accordingly, the limits on mechanical index (an estimate of the potential to produce macro streaming and cavitation) and thermal index (a ratio relating power output to the ability to raise tissue temperature 
by $1{ }^{\circ} \mathrm{C}$ ) for applications around the eye have been reduced from 6.0 and 1.9 to 0.23 and $<1$, respectively.

Early model portable ultrasonic devices used for peripheral nerve blocks were not routinely equipped with orbital-rated transducers. In a rabbit model study, Palte et al compared thermal and mechanical changes induced by the use of ophthalmic-rated and nonophthalmic-rated transducers. ${ }^{44} \mathrm{He}$ demonstrated significant changes in intraorbital temperature following moderate exposure to a nonorbital rated high frequency $(6-13 \mathrm{MHz})$ transducer. Fortunately, late model portable ultrasound devices are suited to the eye examination because they limit transducer power output within recommended guidelines when set to "eye examination" mode.

Najman et al conducted a prospective study of ultrasoundassisted periconal ocular block in a rabbit model ${ }^{45}$ The periconal technique, first described by Davis and Mandel in 1986, is a modification of the peribulbar block in which a longer needle is advanced behind the eye but remains outside of the extraocular muscle cone ${ }^{46}$ In all 18 rabbits, the needle and the spread of local anesthetic were satisfactorily visualized without complication. The investigators also recorded IOP and found no statistical differences between pre- and postblock values. More recently, Najman et al performed a randomized controlled human trial of periconal eye blocks with and without ultrasound guidance. ${ }^{47}$ One hundred and twenty-nine patients were assigned to undergo periconal block, with or without ultrasound guidance, using a $25 \mathrm{~mm}$ (shorter than retrobulbar) needle. Although there was no difference in the complication rate, sonic guidance was considered beneficial because it resulted in shallower depths of needle insertion and reduced incidences of intraconal needle placement.

In another prospective study, Luyet et al performed ultrasonic examinations of peribulbar local anesthetic spread in 100 patients undergoing posterior segment surgery ${ }^{48}$ Despite a $28 \%$ initial block failure rate, Luyet et al was able to clearly demonstrate that there was instantaneous intraconal spread of the LA deposited at extraconal sites. In a similar fashion to Winder et $\mathrm{al},{ }^{42}$ he demonstrated that LA diffluent produced an optic perineural "T" sign (Figure 2). Of importance, the visualization of this " $\mathrm{T}$ " sign bore excellent correlation with block success. The translational significance of this observation is that real-time ultrasonography offers a definitive "end-point" for the administration of local anesthetic and facilitates effective ocular anesthesia at lower LA volumes.

Despite these advantages, a number of challenges still confront the anesthesiologist eager to perform ultrasound-guided eye blocks. First, the cost of acquiring an orbital-rated device may be financially burdensome. Second, a high-frequency transducer $(>12 \mathrm{MHz})$ is required because it provides higher resolution of superficial orbital contents; furthermore, the footprint of this transducer must seat comfortably on the eyelid. This means that most linear transducers used for peripheral nerve blocks are not suitable for eye blocks. Third, positioning of the transducer on the eyelid can be cumbersome, and the ability to identify and track the needle trajectory is not guaranteed, especially, with finer gauge needles. Fourth, in order to perform real-time visualization of needle trajectory and LA dispersion, a second operator must maintain transducer immobility during injection. Finally, ultrasound-guided eye blocks take longer to perform because of set-up and scanning delays. However, the time required to complete these blocks is greatly reduced as one becomes more familiar with the technique.

\section{Sub-Tenon's anesthesia}

The STBs or episcleral block was first described by Turnbull in 1884 and for many years received little attention. However, it was repopularized in the 1990s as a simple and safe alternative to needle-based eye blocks. ${ }^{49}$ In the United Kingdom, the STB is the most widely practiced regional
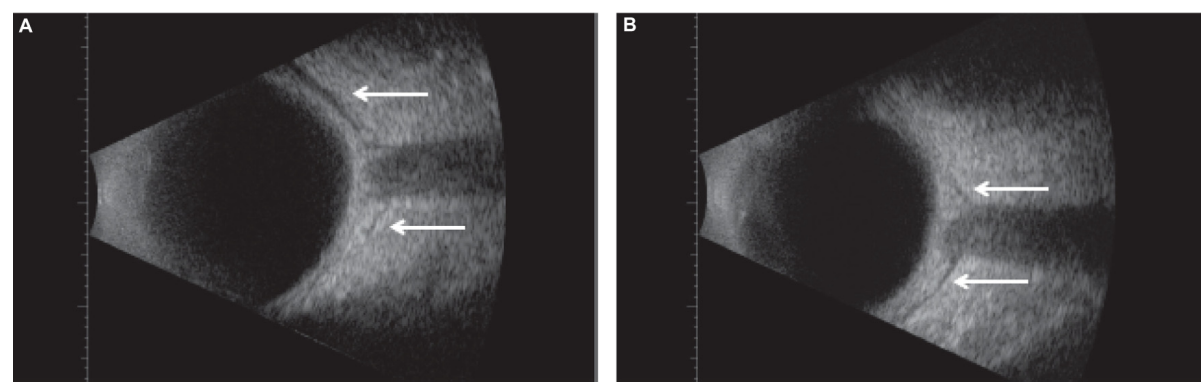

Figure 2 B-mode scan ultrasound images with arrows indicating expanded sub-Tenon's space and apparent "T-sign" following standard sub-Tenon block (A) and incisionless sub-Tenon technique (B).

Notes: Reprinted by permission from Macmillan Publishers Ltd: Eye. Lin S, Ling RH, Allman KG. Real-time visualization of anaesthetic fluid localization following incisionless sub-Tenon's block. Eye (Lond). 20I4;28(4):497-498. Copyright (C 2014 Royal College of Ophthalmologists. ${ }^{57}$

Abbreviation: B, brightness. 
technique for cataract surgery. ${ }^{50}$ The reasons for the major resurgence of interest in this block are first, it produces satisfactory anesthesia for most intraocular procedures; second, it avoids the inherent risks of needle-based blocks, such as globe perforation and optic nerve injury.

\section{Anatomy}

Tenon's capsule is a fascial layer of connective tissue that surrounds the globe and invests the extraocular muscles. Anteriorly, the capsule fuses to the conjunctiva a few millimeters posterior to the limbal margin. At the posterior pole, the layer terminates at or near the point where the optic nerve enters the globe. The potential space that exists between the rigid sclera and the capsule is known as the STB's or episcleral space. The space contains a trabecular meshwork that is filled with lymphatic fluid that provides a low-resistance milieu for globe excursion. The capsule receives innervation from the short ciliary nerves that penetrate its posterior portion en route to the globe. Akinesia is presumably achieved by the blockade of motor nerves as they traverse the space prior to innervating the extraocular muscles.

\section{Procedure}

The block is performed with an intravenous cannula in situ and the patient in the supine position. The conjunctiva is desensitized with topical anesthetic solution, and the field is decontaminated with a few povidone-iodine drops. The technique traditionally involves making a conjunctival incision (often in the infero-nasal quadrant) with blunt-tipped Westcott scissors and bluntly dissecting the ST layer off the sclera. Then, a blunt cannula is introduced into the ST's space, and local anesthetic is administered. The passage of LA has been studied using multiple imaging techniques. ${ }^{51,52}$ These demonstrate that injected local anesthetic spreads across the potential ST space and produces anesthesia and akinesia by diffusing into intra and extraconal zones.

The choice of cannula for STB is a matter of personal preference. Commercially available models differ in their construction material, flexibility, shape, and length. ${ }^{53}$ While some are straight, others are contoured (conform to the shape of the globe) or rigid and metallic (ease of insertion). The STB produces excellent analgesia but variable degrees of akinesia. ${ }^{54,55}$ In recent years, Allman et al has described a new and less invasive incisionless technique for STB. ${ }^{56}$ The advantage of this technique is that no conjunctival incision is made. Instead, the ST's space is accessed via a blunt "pencil-point" cannula, which is inserted directly through the conjunctiva and advanced around the contour of the globe. In a study comparing STB via the standard approach requiring conjunctival incision and the incision-free approach, Lin found similar rates of block success with no differences in the quality of ocular akinesia. Furthermore, real-time B-mode visualization of post-block LA spread demonstrated no differences between the techniques. Lin commented that the Allman et al's incisionless technique offers the advantages of reduced conjunctival trauma, diminished anterior reflux of LA, and enhanced onset time. ${ }^{57}$

The STB is associated with a number of minor complications. Of these, pain on injection (44\%), chemosis $(2 \%-60 \%)$, subconjunctival hemorrhage $(>20 \%)$, and over spillage of LA during administration are the most common. The incidence of chemosis varies with the volume of LA, dissection technique, and choice of cannula. It has been reported that there is a $10 \%-15 \%$ reduction in ocular pulsatile flow during the injection phase of the STB, but the clinical significance of this finding is undetermined. Sight and lifethreatening complications of STB are rare but have been reported. These include temporary muscle paresis, orbital and retrobulbar hemorrhage, and scleral perforation. ${ }^{58-60}$ In 2007, Quantock and Goswami reported a death following a ST's block in which it was postulated that brainstem anesthesia occurred secondary to retrograde LA spread within the optic nerve sheath. ${ }^{61}$

In summary, the STB is administered primarily for cataract surgery but is also effective in a variety of other eye surgeries, including vitreoretinal surgery, strabismus correction, and trabeculectomy. It eliminates the risk of globe and adnexal injury associated with sharp needles and produces predictable anesthesia that is easily supplemented intraoperatively for extended postoperative analgesia. Recent reviews suggest that it can be safely used in patients receiving Ac and Ap therapy. ${ }^{62}$ Although the STB is associated with a measurable incidence of residual eye movement, this does not affect the conduct of most surgeries. The block may present technical difficulties in patients who have undergone prior scleral buckle procedures for repair of retinal detachment, those with implanted glaucoma drainage devices, and those who have received a ST's block in the past. ${ }^{63}$

\section{HA and allergy}

The enzyme HA is an adjuvant added to LA in order to improve the efficacy and onset of nerve blocks. The enzyme catalyzes the hydrolysis of hyaluronic acid, a key constituent of the interstitial barrier. Its action lowers the viscosity of hyaluronic acid resulting in increased tissue permeability. Furthermore, it alkalinizes local anesthetic through the 
presence of phosphate buffers, and may account for an observed acceleration in block onset. HA is found in the saliva and venom of several biting or stinging insects, and is often identified as the causative allergen in patients who develop hypersensitivity reactions to insect attack.

In the 1940s, Atkinson described the addition of HA to LA for retrobulbar and lid blocks. ${ }^{64}$ Several studies have evaluated the efficacy of differing concentrations of HA in retrobulbar block. In a group of 100 patients, Nicoll et al studied the addition of $15 \mathrm{IU} \mathrm{mL}^{-1} \mathrm{HA}$, and showed improved akinesia at 10 minutes. ${ }^{65}$ Abelson et al used $60 \mathrm{IU} \mathrm{mL}^{-1}$ and found that it accelerated block onset with superior akinesia. ${ }^{66}$ Krohn et al used $150 \mathrm{IU} \mathrm{mL} \mathrm{m}^{-1} \mathrm{HA}$ in low volume retrobulbar blocks and failed to demonstrate improved akinesia or analgesia. ${ }^{67}$ Dempsey et al evaluated the efficacy of HA for peribulbar blockade by comparing a control group with two groups in which the enzyme was added in concentrations of $50 \mathrm{IU} \mathrm{mL} \mathrm{m}^{-1}$ and $300 \mathrm{IU} \mathrm{mL} \mathrm{m}^{-1}{ }^{68} \mathrm{He}$ found significant reductions of ocular motility at 5 minutes in the $300 \mathrm{IU} \mathrm{mL}^{-1}$ group. In a randomized trial, Kallio et al compared $3.75 \mathrm{IU} \mathrm{mL}^{-1}$ and $7.5 \mathrm{IU} \mathrm{mL}^{-1}$ in peribulbar and retrobulbar blocks and demonstrated improved akinesia with reduced requirements for supplemental block in both groups. ${ }^{69}$

The role of HA has also been extensively studied in ST's block. Guise and Laurent evaluated $30 \mathrm{IU} \mathrm{mL} \mathrm{m}^{-1} \mathrm{HA}$ added to a $5 \mathrm{~mL} \mathrm{STB}$ and showed improved akinesia at $3 \mathrm{~min}-$ utes. $^{70}$ Rowley et al performed a randomized control trial of $30 \mathrm{IU} \mathrm{mL} \mathrm{m}^{-1} \mathrm{HA}$ added to STB for patients undergoing cataract extraction and found improved akinesia at 10 minutes, but failed to demonstrate any significant difference in pain scores. $^{71}$

Allergic reactions to HA are a rare but recognized complication of its use. The true incidence of HA allergy is difficult to determine because mild cutaneous responses are frequently mistaken for reactions to other topical preparations. Most patients experiencing allergic reactions report an uneventful prior exposure to hyaluronic acid, implying that sensitization has taken place. However, reactions on initial exposure are possible suggesting that allergy is mediated via both Type 1 and Type IV hypersensitivity. Common HA allergic manifestations include conjunctival injection with chemosis (Figure 3), periorbital edema (Figure 4), pruritus, pain, and restriction of extraocular muscle motility.

In 2012, Dieleman et al reported a cluster of 44 Dutch patients presenting with orbital inflammatory signs and symptoms after uneventful ophthalmic surgery. ${ }^{72}$ On investigation, it was discovered that in all cases, $150-300 \mathrm{IU} \mathrm{mL}^{-1}$ HA had been added to the anesthetic mixture. Skin patch

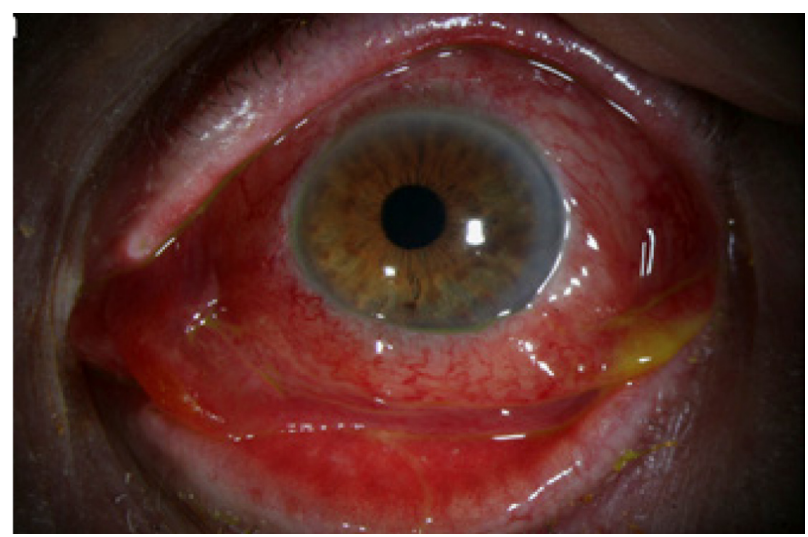

Figure 3 Hyaluronidase allergy: conjunctival injection and chemosis.

Notes: Adapted by permission from Macmillan Publishers Ltd: Eye. A sting in the tale: cross reaction hypersensitivity to hyaluronidase. Lyall DAM, McQueen M, Ramesh K, Weir C. Eye. 2012;26:1490. Copyright (C) 2012 Macmillan Publishers Limited All rights reserved. ${ }^{83}$

allergy testing and the fact that all cases received HA from a single batch suggested that HA was the offending agent. Allergic HA responses have also been reported after STB. Park and Lim described a rare case of delayed orbital inflammation associated with raised $\mathrm{IOP}^{73}$ Although rare, all reported cases of post-STB HA allergy presented with delayed onset of periorbital inflammation, suggesting that responses may be due to a combination of type 1 and type 4 hypersensitivity. It is impossible to predict which patients are at risk of allergic HA reactions because these events are extremely infrequent, mediated via alternate pathways, and many patients have an uneventful prior exposure to HA. Two preemptive measures worthy of consideration are first, using $\mathrm{HA}$ at reduced concentrations $\left(5-15 \mathrm{IU} \mathrm{mL}^{-1}\right)$; second, abandoning the use of ovine and bovine HA preparations in favor of recombinant HA, which reduces allergic and toxic

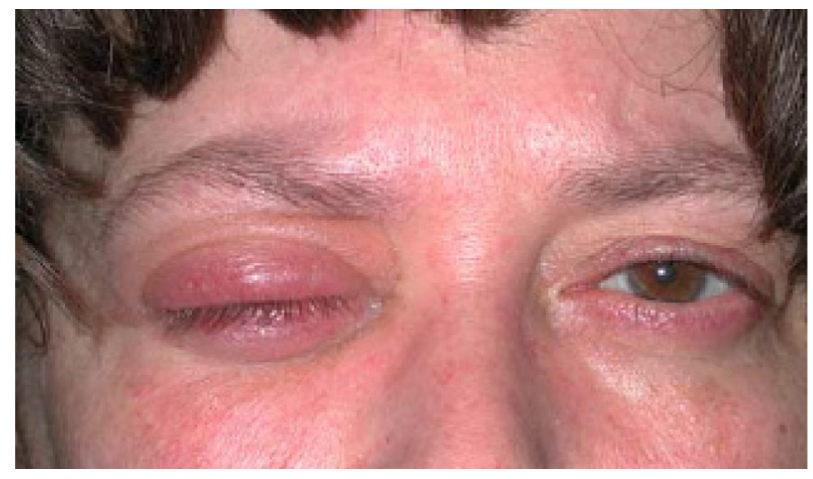

Figure 4 Hyaluronidase allergy: periorbital swelling.

Notes: Copyright (C) Springer Science+Business Media B.V. 2008. Reproduced from: Allergic reaction to hyaluronidase after retrobulbar anaesthesia: a case series and review. International Ophthalmology; volume 29, 2009, pages 521-528; Delaere L, Zeyen T, Foets B, Van Calster J, Stalmans I. With permission of Springer Science+Business Media. ${ }^{84}$ 
reactions because it eliminates the immune trigger of the animal extracted enzyme. ${ }^{74}$

\section{Needle block complications}

Needle-based eye blocks are still commonly practiced despite the growing interest in episcleral anesthesia. Most anesthesiologists and increasing numbers of ophthalmologists are abandoning the retrobulbar block in favor of the peribulbar (extraconal) block. The major complications of ophthalmic blocks are either life or sight threatening. The former group includes brainstem anesthesia (central block), acute seizure activity, and cranial nerve block. A keen awareness and recognition of these complications coupled with early supportive intervention will often limit the severity and long-term sequelae of these complications. While not discounting the gravity of life-threatening complications, the more pressing challenge for the regional ophthalmic anesthesiologist is the avoidance of sight-threatening misadventures. This group of complications includes retro- and peribulbar hemorrhage, ocular penetration and perforation, retinal vascular spasm, optic nerve injury, and ocular myotoxicity.

\section{Retrobulbar and peribulbar hemorrhage}

The reported incidence of retro/peribulbar hemorrhage varies between $1 \%$ and $3 \% .{ }^{32}$ Major bleeding is less common after peribulbar block and when it does occur it rarely produces elevations of IOP. However, retrobulbar hemorrhage may be associated with visual loss that takes place from orbital compression and impairment of ophthalmic artery circulation. In an audit of more than 12,000 retrobulbar blocks, Edge and Nicoll reviewed the incidence and associations for retrobulbar hemorrhage. ${ }^{75}$ He found that patients with acquired vascular disease were at a significantly greater risk of periocular bleeding, whereas diabetics presented only a marginal risk of serious hemorrhage. Additionally, he was able to subcategorize block-induced periocular bleeding into three groups: 1) minor hemorrhage caused by damage to a vein or small artery that produces a palpable elevation in IOP, 2) arterial hemorrhage producing rapid proptosis and raised IOP, and 3) concealed hemorrhage in which blood remains within the muscular cone and produces elevations in IOP without visible evidence of orbital hemorrhage. Treatment of retrobulbar hemorrhage is dependent on the severity of the bleed and assessed the risk of ocular circulatory compromise. In all cases, it is vital to apply immediate external ocular external pressure at the bedside. Additional interventional treatment options include intravenous mannitol, lateral canthotomy, and anterior chamber paracentesis.

\section{Ocular penetration and perforation}

The incidence of direct globe injury ranges from 1:1,000 to $1: 12,000 .^{76}$ It is believed that the risk of perforation is up to 30 times greater in myopia because the sclera is thinner, and the orbit has a greater antero-posterior diameter. However, in a review of 50,000 eye blocks, Edge and Navon found that myopia is only a significant risk factor for inadvertent perforation when associated with staphyloma. ${ }^{77}$ This observation underscores the benefit of preoperative ultrasound scanning in myopic patients. Furthermore, there is an increased risk of perforation associated with enophthalmos, and in patients who have undergone prior scleral buckle procedure. In a retrospective review of 33,363 peribulbar blocks, Riad and Akbar discovered globe perforations occurred in eight of the 23 needle-related complications $(0.026 \%){ }^{78}$

In general, perforation produces vitreous hemorrhage and pain. Although perforation is classically associated with hypotony $(30 \%)$, retinal detachment $(55 \%)$, or sudden increases in IOP (10\%), the diagnosis is often delayed and only made at the postoperative examination. Duker et al reviewed the clinical features and outcomes of globe perforations. Interestingly, they found that in almost $50 \%$ of perforations, the surgeon was unaware of injury at the time of surgery. ${ }^{79}$ Needle perforations tend to be associated with poor visual outcome. On these grounds, the STB is touted as a safer regional technique. However, there have been several case reports of STB-related misadventure ranging from retrobulbar hemorrhage, ${ }^{59}$ globe perforation, ${ }^{60}$ muscle trauma,${ }^{80}$ and postoperative diplopia. ${ }^{81}$ The risk of needle injury to the globe is not limited to block technique because patient movement during performance of the block is a real risk and the basis for litigation. ${ }^{82}$ The anesthesiologist must remain cognizant that all regional ophthalmic techniques carry risk, and constantly assess whether selection of a particular technique is optimal. Experience is the cornerstone of reflection and adaptability.

\section{Conclusion}

In summary, the shifting landscape of eye surgery presents new and unique challenges for the ophthalmic anesthesiologist. The sun has set on the landscape of eye surgery performed under GA at teaching hospitals. In its place, a new dawn has ushered the panorama of eye surgery conducted under regional block at specialty eye care day centers. In future, anesthesiologists will bear responsibility for managing greater patient volumes, overseeing cost containment initiatives, and meeting demands for improved OR efficiency. Consequently, as a component of this expanded role, anesthesiologists will 
be expected to perform eye blocks in the holding suite. In meeting these challenges, teaching departments will need to revamp their curricula so that residents become skilled in performing eye blocks, and anesthesia societies will need to ensure that ophthalmic regional seminars and workshops are more available.

\section{Disclosure}

The author declares no conflicts of interest.

\section{References}

1. Cullen KA, Hall MJ, Golosinskiy A. Ambulatory Surgery in the United States, 2006; 2009. National Health Statistics Report No 11 January 28, 2009-Revised September 4. Hyattsville, MD: US Department of Health \& Human Services; 2009.

2. Miller-Meeks MJ, Bergstrom T, Karp KO. Prevalent attitudes regarding residency training in ocular anesthesia. Ophthalmology. 1994;101:1353.

3. Grizzard WS, Kirk NM, Pavan PR, Antworth MV, Hammer ME, Roseman RL. Perforating ocular injuries caused by anesthesia personnel. Ophthalmology. 1991;98:1011.

4. Hay A, Flynn HW Jr, Hoffman JI, Rivera AH. Needle penetration of the globe during retrobulbar and peribulbar injections. Ophthalmology. 1991;98(7):1017-1024.

5. Bhananker SM, Posner KL, Cheney FW, Caplan RA, Lee LA, Domino KB. Injury and liability associated with monitored anesthesia care: a closed claims analysis. Anesthesiology. 2006;104(2):228-234.

6. Lee LA, Posner KL, Cheney FW, Caplan RA, Domino KB. Complications associated with eye blocks and peripheral nerve blocks: an American Society of Anesthesiologists closed claim analysis. Reg Anesth Pain Med. 2008;33(5):416-422.

7. McGwin G Jr, Owsley C. Incidence of emergency departmenttreated eye injury in the United States. Arch Ophthalmol. 2005;123: $662-666$.

8. Lincoff HA, Breinin GM, Devoe AG. The effect of succinylcholine on the extraocular muscles. Am J Ophthalmol. 1957;43:440-444.

9. Dillon JB, Gunter R, Sabawala P, Taylor DB. Action of succinylcholine on extraocular muscles and intraocular pressure. Anesthesiology. 1957;18:44-49.

10. Moreno RJ, Kloess P, Carlson DW. Effect of succinylcholine on the intraocular contents of open globes. Ophthalmology. 1991;98:636-638.

11. Libonati MM, Leahy JJ, Ellison N. The use of succinylcholine in open eye surgery. Anesthesiology. 1986;62:637-640.

12. Pieramici DJ, Sternberg P Jr, Aaberg TM Sr, et al. A system for classifying mechanical injuries of the eye (globe). The Ocular Trauma Classification Group. Am J Ophthalmol. 1997;123:820-831.

13. Scott IU, Mccabe CM, Flynn HW, et al. Local anesthesia with intravenous sedation for surgical repair of selected open globe injuries. Am J Ophthalmol. 2002;134(5):707-711.

14. Scott IU, Gayer S, Voo I, Flynn HW Jr, Diniz JR, Venkatraman A. Regional anesthesia with monitored anesthesia care for surgical repair of selected open globe injuries. Ophthalmic Surg Lasers Imaging. 2005;36(2):122-128.

15. Toung TJ, Rossberg MI, Hutchins GM. Volume of air in a lethal air embolism. Anesthesiology. 2001;94:360-361.

16. Ledowski T, Kiese F, Jeglin S, Scholz J. Possible air embolism during eye surgery. Anesth Analg. 2005;100:1651-1652.

17. Ruest P, Aroichane M, Cordahi G, Bureau N. Possible venous air embolism during open eye surgery in a child. Can J Anaesth. 2007;54(10): 840-844.

18. Dermigny F, Daelman F, Guinot PG, et al. Fatal air embolism during open eye surgery (in French). Ann Fr Anesth Reanim. 2008;27(10): 840-842.
19. Lim LT, Somerville GM, Walker JD. Venous air embolism during air/ fluid exchange: a potentially fatal complication. Arch Ophthalmol. 2010;128(12):1618-1619.

20. Morris RE, Sapp MR, Oltmanns MH, Kuhn F. Presumed air by vitrectomy embolization (PAVE) a potentially fatal syndrome. $\mathrm{Br} J$ Ophthalmol. 2014;98(6):765-768.

21. Zhou Y, Boudreau DM, Freedman AN. Trends in the use of aspirin and nonsteroidal anti-inflammatory drugs in the general US population. Pharmacoepidemiol Drug Saf. 2014;23(1):43-50.

22. Connolly SJ, Ezekowitz MD, Yusuf S. Dabigatran versus warfarin in patients with atrial fibrillation. N Engl J Med. 2009;361:1139-1151.

23. Oldgren J, Budaj A, Granger CB, et al; RE-DEEM Investigators. Dabigatran versus placebo in patients with acute coronary syndromes on dual antiplatelet therapy: a randomized, double-blind, phase II trial. Eur Heart J. 2011;32:2781-2789.

24. Kubitza D, Becka M, Mueck W, Zuelhsdorf M. Rivarobaxan (BAY 59-7939) - an oral, direct factor Xa inhibitor - has no clinically relevant interaction with naproxen. Br J Clin Pharmacol. 2007;63:469-476.

25. EINSTEIN Investigators; Bauersachs R, Berkowitz SD, Brenner B, et al. Oral rivarobaxan for symptomatic venous thromboembolism. N Engl J Med. 2010;363:2499-2510.

26. Mega JL, Braunwald E, Wiviott SD, et al; ATLAS ACS2-TIMI 51 Investigators. Rivarobaxan in patients with recent acute coronary syndrome. N Engl J Med. 2012;365:883-891.

27. Connolly SJ, Eikebbom J, Joyner C, et al; AVERROES Steering Committee and Investigators. Apixaban in patients with atrial fibrillation. N Engl J Med. 2011;364:806-817.

28. Granger CB, Alexander JH, McMurray JJ, et al; ARISTOTLE Committees and Investigators. Apixaban versus warfarin in patient with atrial fibrillation. N Engl J Med. 2011;365:981-992.

29. Calenda E, Genevois O, Cardon A, Muraine M. Peribulbar anesthesia in 750 patients treated with oral anticoagulants. Int J Ophthalmol. 2014; 7(1):110-113.

30. Brown JS, Mahmoud TH. Anticoagulation and clinically significant postoperative vitreous hemorrhage in diabetic vitrectomy. Retina. 2011;31(10):1983-1987.

31. Mason JO 3rd, Gupta SR, Compton CJ, et al. Comparison of hemorrhagic complications of warfarin and clopidogrel bisulfate in 25-gauge vitrectomy versus a control group. Ophthalmology. 2011;118(3):543-547.

32. Kallio H, Paloheimo M, Mauniksela E-L. Hemorrhage and risk factors associated with retrobulbar/peribulbar block: a prospective study in 1383 patients. Br J Anaesth. 2000;85(5):708-711.

33. Benzimra JD, Johnston RL, Jaycock P, et al; EPR User Group. The Cataract National dataset electronic mutlicentre audit of 55 567 operations: antiplatelet and anticoagulant medications. Eye. 2009;23(1):10-16.

34. Oh J, Smiddy WE, Kim SS. Antiplatelet and anticoagulation therapy in vitreoretinal surgery. Am J Ophthalmol. 2011;151(6):934-939.

35. Gerstein NS, Schulman PM, Gerstein WH, Petersen TR, Tawil I. Should more patients continue aspirin therapy perioperatively? Clinical impact of aspirin withdrawal syndrome. Ann Surg. 2012;255(5):811-819.

36. Baron TH, Kamath PS, McBane RD. Management of antithrombotic therapy in patients undergoing invasive procedures. $N$ Engl $\mathrm{J} \mathrm{Med}$. 2013;368(22):2113-2124.

37. McClellan AJ, Flynn HW Jr, Smiddy WE, Gayer SI. The use of antithrombotics in posterior segment ocular surgery. Am J Ophthalmol. 2014;158(5):858-859.

38. Kong K-L, Khan J. Ophthalmic patients on antithrombotic drugs: a review and guide to perioperative management. Br J Ophthalmol. Epub 2014 Nov 25.

39. Birch AA, Evans M, Redembo E. The ultrasonic localization of retrobulbar needles during retrobulbar block. Ophthalmology. 1995;102(5): $824-826$.

40. Vohra SB, Good PA. Altered globe dimensions of axial myopia as risk factors for penetrating ocular injury during peribulbar anaesthesia. Br J Anaesth. 2000;85(2):242-245. 
41. Palte HD, Gayer S. Chemosis secondary to anterograde episcleral (sub-Tenon) spread of local anesthetic during retrobulbar eye block. Anesthesiology. 2014;121(4):877.

42. Winder S, Walker SB, Atta HR. Ultrasonic localization of anesthetic fluid in sub-Tenon's, peribulbar, and retrobulbar techniques. J Cataract Refract Surg. 1999;25(1):56-59.

43. Luyet C, Eichenberger U, Moriggl B, Remonda L, Greif R. Real-time visualization of ultrasound-guided retrobulbar block: an imaging study. Br J Anaesth. 2008;101(6):855-859.

44. Palte HD, Gayer S, Arrieta E, et al. Are ultrasound-guided ophthalmic blocks injurious to the eye? A comparative rabbit model study of two ultrasound devices evaluating intraorbital thermal and structural changes. Anesth Analg. 2012;115(1):194-201.

45. Najman IE, Ferreira JZ, Abimussi CJ, et al. Ultrasound-assisted periconal ocular blockade in rabbits. Vet Anaesth Analg. 2015;42(4):433-441.

46. Davis DB 2nd, Mandel MR. Posterior peribulbar anesthesia: an alternative to retrobulbar anesthesia. J Cataract Refr Surg. 1986;12: $182-184$

47. Najman IE, Meirelles R, Ramos LB, Guimaraes TCF, do Nascimento P Jr. A randomized controlled trial of periconal eye blockade with or without ultrasound guidance. Anaesthesia. 2015.

48. Luyet C, Eng KT, Kertes PJ, Avila A, Muni RH, Mchardy P. Real-time evaluation of diffusion of the local anesthetic solution during peribulbar block using ultrasound imaging and clinical correlates of diffusion. Reg Anesth Pain Med. 2012;37(4):455-459.

49. Stevens JD. A new local anesthesia technique for cataract extraction by one quadrant sub-Tenon's infiltration. Br J Ophthalmol. 1992;76(11):670-674.

50. Eke T, Thompson JR. Serious complications of local anaesthesia for cataract surgery: a 1 year national survey in the United Kingdom. $\mathrm{Br} J$ Ophthalmol. 2007;91:470-475.

51. Kumar CM, McNeela BJ. Ultrasonic localization of anesthetic fluid using sub-Tenon's cannulae of three different lengths. Eye. 2003;17(9):1003-1007.

52. Niemi-Murola L, Krootila K, Kivisaari R, Kangasmäki A, Kivisaari L, Maunuksela EL. Localization of anesthetic solution by magnetic resonance imaging. Ophthalmology. 2004;111(2):342-347.

53. Kumar CM, Dodds C, McLure H, Chabria R. A comparison of three sub-Tenon's cannulae. Eye. 2004;18(9):873-876.

54. Tan CS, Au Eong KG, Kumar CM. Visual experiences during cataract surgery: what anesthesia providers should know. Eur J Anaesthesiol. 2005;22(6):413-419.

55. Kumar CM, Dodds C. Sub-Tenon's anesthesia. Ophthalmol Clin North Am. 2006;19:209-219.

56. Allman KG, Theron AD, Byles DB. A new technique of incisionless minimally invasive sub-Tenon's anaesthesia. Anaesthesia. 2008;63(7): 782-783.

57. Lin S, Ling RH, Allman KG. Real-time visualization of anaesthetic fluid localization following incisionless sub-Tenon's block. Eye (Lond). 2014;28(4):497-498.

58. Spierer A, Schwalb E. Superior oblique muscle paresis after sub-Tenon's anesthesia for cataract surgery. J Cataract Refr Surg. 1999;25(1): 144-145.

59. Olitsky SE, Juneja RG. Orbital hemorrhage after the administration of sub-Tenon's infusion anesthesia. Ophthalmic Surg Lasers. 1997;28(2):145-146.

60. Frieman BJ, Friedberg MA. Globe perforation associated with subtenon's anesthesia. Am J Ophthalmol. 2001;131(4):520-521.

61. Quantock CL, Goswami T. Death potentially secondary to sub-Tenon's block. Anaesthesia. 2007;62(2):175-177.

62. Kumar C, Dowd T. Ophthalmic regional anesthesia. Curr Opin Anaesthesiol. 2008;21(5):632-637.
63. Guise P. Sub-Tenon's anesthesia: an update. Local Reg Anesth. 2012;5:35-46.

64. Atkinson WS. Use of hyaluronidase with local anaesthesia in ophthalmology; preliminary report. Arch Ophthalmol. 1949;42(5): 628-633.

65. Nicoll JM, Treuren B, Acharya PA, Ahlen K, James M. Retrobulbar anesthesia: the role of hyaluronidase. Anesth Analg. 1986;65(12): 1324-1328.

66. Abelson MB, Mandel E, Paradis A, George M. The effect of hyaluronidase on akinesia during cataract surgery. Ophthalmic Surg. 1989;20(5):325-326.

67. Krohn J, Seland JH, Høvding G, Bertelsen T, Aasved H, Haugen OH. Retrobulbar anesthesia with and without hyaluronidase in extracapsular cataract surgery. A prospective, randomized, double blind study. Acta Ophthalmol. 1993;71(6):791-795.

68. Dempsey GA, Barrett PJ, Kirby IJ. Hyaluronidase and peribulbar block. Br J Anaesth. 1997;78(6):671-674.

69. Kallio H, Paloheimo M, Maunuksela EL. Hyaluronidase as an adjuvant in bupivacaine-lidocaine mixture for retrobulbar/peribulbar block. Anesth Analg. 2000;91(4):934-937.

70. Guise P, Laurent S. Sub-Tenon's block: the effect of hyaluronidase on speed of onset and block quality. Anaesth Intensive Care. 1999;27(2): 179-181.

71. Rowley SA, Hale JE, Finlay RD. Sub-Tenon's local anaesthesia: the effect of hyaluronidase. Br J Ophthalmol. 2000;84(4):435-436.

72. Dieleman M, Bettink-Remeijer MW, Jansen J, et al. High incidence of adverse reactions to locoregional anaesthesia containing hyaluronidase after uneventful ophthalmic surgery. Acta Ophthalmol. 2012;90(3):e245-e246.

73. Park S, Lim LT. Orbital inflammation secondary to a delayed hypersensitivity reaction to sub-Tenon's hyaluronidase. Semin Ophthalmol. 2014;29(2):57-58.

74. Palte HD, Greenbaum S, Gayer S. Recombinant hyaluronidase. Clin Experiment Ophthalmol. 2014;42(3):298.

75. Edge KR, Nicoll JM. Retrobulbar hemorrhage after 12,500 retrobulbar blocks. Anesth Analg. 1993;76:1019-1022.

76. Eke T, Thompson JR. The national survey of local anaesthesia for ocular surgery. II. Safety profiles of local anaesthesia techniques. Eye. 1999; 13:196-204.

77. Edge R, Navon S. Scleral perforation during retrobulbar and peribulbar anesthesia: risk factors and outcome in 50,000 consecutive injections. J Cataract Refract Surg. 1999;25(9):1237-1244.

78. Riad W, Akbar F. Ophthalmic regional blockade complication rate: a single center audit of 33,363 ophthalmic operations. J Clin Anesth. 2012;24(3):193-195.

79. Duker JS, Belmont JB, Benson WE, et al. Inadvertent globe perforation during retrobulbar and peribulbar anesthesia. Patient characteristics, surgical management, and visual outcome. Ophthalmology. 1991;98: 519-526.

80. Jaycock PD, Mather CM, Ferris JD, Kirkpatrick JN. Rectus muscle trauma complicating sub-Tenon's local anaesthesia. Eye. 2001;15: 583-586.

81. Blum RA, Lim LK, Weir CR. Diplopia following sub-Tenon's anaesthesia: an unusual complication. Int Ophthalmol. 2012;32:191-193.

82. Gayer S. Key components of risk associated with ophthalmic anesthesia. Anesthesiology. 2006;105:859.

83. A sting in the tale: cross reaction hypersensitivity to hyaluronidase. Lyall DAM, McQueen M, Ramesh K, Weir C. Eye. 2012;26:1490.

84. Allergic reaction to hyaluronidase after retrobulbar anaesthesia: a case series and review. Delaere L, Zeyen T, Foets B, Van Calster J, Stalmans I. Int Ophthalmol. 2009;29:521-528. 


\section{Publish your work in this journal}

Local and Regional Anesthesia is an international, peer-reviewed, open access journal publishing on the development, pharmacology, delivery and targeting and clinical use of local and regional anesthetics and analgesics. The journal welcomes submitted papers covering original research, basic science, clinical studies, reviews \& evaluations,

guidelines, expert opinion and commentary, case reports and extended reports. The manuscript management system is completely online and includes a very quick and fair peer-review system, which is all easy to use. Visit http://www.dovepress.com/testimonials.php to read real quotes from published authors.

Submit your manuscript here: http://www.dovepress.com/local-and-regional-anesthesia-journal 